\section{Budget cuts leave US science lagging}

As a student of science, I'm thrilled that scientists at CERN, Europe's particle-physics lab, have proved the existence of the Higgs boson and advanced our understanding of the Universe. But as an American, I'm somewhat saddened. Had congressional budget-cutters been less short-sighted two decades ago, the Higgs boson might have been discovered by a US-led team instead of by a European consortium. On 4 July, no less.

In 1993, Congress cancelled funding for the Superconducting Super Collider near Waxahachie, Texas, after sinking US $\$ 2$ billion into an 87-kilometre particle accelerator that promised to establish the United States as the leader in physics research. Two years later, funding was approved by CERN to build the Large Hadron Collider near Geneva, Switzerland.

US science is facing a growing threat from a well-funded anti-science movement, abetted by those corporations and politicians opposed to any research that conflicts with their own vested interests.

Apathy towards basic research in the United States is coupled with an increasing reluctance to invest in science projects that do not have a foreseeable pay-off. But let's not forget that the pioneers of quantum mechanics in the 1900s - Niels Bohr, Albert Einstein and Erwin Schrödinger - were unable to offer any practical ideas about commercial uses for the subatomic particles, quarks and leptons they were bringing to light at the time. However, if you are reading this on a computer, tablet or smart phone, you have quantum mechanics to thank.

An estimated 30-35\% of today's US gross domestic product is based on inventions derived from quantum theory, from semiconductors in computer chips and lasers in compact-disc players to magnetic resonance imaging in hospitals and much more.

If it doesn't want to fall behind, the United States should be following the lead of other nations that are investing in science and technology to benefit their economies. William J. Richards Hall Institute of Public Policy, New Jersey, USA. wrichards@hallnj.org

\section{Improve access to sanitation in China}

We hope that last month's raising of drinking-water standards in China will help to speed up improvements in the country's sanitation. As in India, sanitation remains inadequate for a rapidly developing country (Nature 486, 185; 2012).

In 2010, 477 million people in China (36\% of the population) did not have access to improved sanitation such as a ventilated pit latrine or a flush toilet piped to a sewer system (WHO/ UNICEF Progress on Drinking Water and Sanitation, 2012).

There are national disparities as well, with $74 \%$ of people having improved access to sanitation in urban areas in 2010, but only $56 \%$ in rural areas. Provision of sanitation facilities for disabled people is sparse.

China's growing population and urbanization make sewage treatment a particular challenge. Although about $73 \%$ of urban sewage is treated (China Statistical Yearbook on Environment; 2010), more than $95 \%$ of waste water in rural areas drains untreated into rivers and lakes (X. Sun et al. Chinese Agr. Sci. Bull. 26, 384-388; 2010).

The country has now increased its surveillance of freshwater pollution so that the new drinking-water standards can be met. This should catalyse the government into investing more in nationwide sanitation improvements. Hong Yang, Jim A. Wright University of Southampton, UK. hongyanghy@gmail.com Stephen W. Gundry University of Bristol, UK.

\section{Better lives, not just contraceptives}

Last month's London Summit on Family Planning, hosted by the Bill \& Melinda Gates Foundation and the UK government's Department for International Development, has been hailed as a resounding success. A total of US $\$ 2.6$ billion was pledged to provide 120 million women and girls in developing countries with access to family-planning services by 2020 . In measuring the success of this welcome campaign, the delivery of social change should also be taken into account.

The hosts emphasize that results will be rapid and quantifiable, for example in terms of the number of contraceptives supplied. But reducing unwanted pregnancies requires other improvements in women's lives, such as better education for girls and reduced child mortality (J. Drèze and M. Murthi Popul. Dev. Rev. 27, 33-63; 2001), outreach by community-health workers and women's empowerment (see, for example, go.nature.com/ bpjgma), and quality familyplanning programmes. Such factors are harder to quantify.

Focusing simply on what can be measured encourages shortterm, narrow interventions rather than broader, longerterm strategies. For instance, value-for-money criteria make it tempting to sidestep national health-care systems, when supporting these is crucial to the delivery of appropriate technologies in developing countries.

Devi Sridhar University of Oxford, UK.

devi.sridhar@wolfson.ox.ac.uk

Karen Grépin New York

University, USA.

\section{Bat deaths from wind turbine blades}

You suggest that wind turbines kill bats as a result of air-pressure changes when they fly through the wake of a spinning blade (the barotrauma hypothesis). However, this is likely to be only a minor cause of bat deaths (Nature 486, 310-311; 2012).

The barotrauma hypothesis has been criticized as based on erroneous interpretations of bat injuries (K. E. Rollins et al. Vet. Pathol. 49, 362-371; 2012). Evidence from bat carcasses shows that bluntforce trauma from the spinning blades is a much more common killing mechanism (see also S. M. Grodsky et al. J. Mammal. 92, 917-925; 2011).

We hope that this finding will be useful in mitigating the effects of wind turbines on bat mortality.

Angelo Capparella, Sabine

Loew Illinois State University, Normal, Illinois, USA. apcappar@ilstu.edu David K. Meyerholz University of Iowa, Iowa City, USA.

\section{Giants all around - apart from the squid}

A smile would have crossed the late Andrew Huxley's face at your description of his "experiments on the axon of the giant squid" (Nature 486, 10-11; 2012). Huxley was giant, the axon was giant, but the squid were quite average in size.

Jonathan C. Horton University of California, San Francisco, California, USA.

hortonj@vision.ucsf.edu

\section{CONTRIBUTIONS}

Correspondence may be sent to correspondence@ nature.com after consulting the guidelines at go.nature. com/cmchno. Alternatively, readers may comment online: nature.com/nature. 